\title{
Accounting For Stock Options: Comparison Of Alternative Approaches
}

Gerald J. Lobo, (E-mail: globo@som.syr), Syracuse University Syracuse Joseph C. Rue, (E-mail: jrue@fgcu.edu), Florida Gulf Coast University

\begin{abstract}
The Financial Accounting Standards Board in Standard No. 123 requires the disclosure of the annual option expense assuming a market based static model is used to measure the option "value" at issue data. This study reviews and tests alternative measures of accounting for stock options that were previously proposed by the Board. Our results suggest the exercise date model provides a measure of option expense which more consistently reflexes the changes in the market value of the option.
\end{abstract}

\section{Introduction}

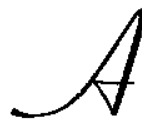

ccounting for employee stock options has been a source of controversy since Accounting Research Bulletin No. 37 was issued in November, 1948. Subsequent pronouncements, Accounting Principles Board (APB) Opinion No. 25_(1972), and Financial Accounting Standards Board (FASB) Interpretation No. 28 (1978), continued not to require that compensation expense for fixed plans be recorded for employee stock options as long as the exercise price equals or exceeds the market price at the date of grant. The controversy continues with the issuance of Statement of Financial Accounting Standards (SFAS) No. 123.

APB Opinion No. 25 requirements can result in vastly different accounting treatments for compensation packages that have similar economic consequences to both the employer and the employee. For example, a company that issues stock appreciation rights (SARs) must re-

Readers with comments or questions are encouraged to contact the authors via e-mail. cord compensation expense for any increase in the market value of the stock between the grant date and the exercise date, whereas, no compensation expense need be recorded for the issuance of a fixed employee stock option with similar consequences.

After four decades, the accounting profession has yet to resolve the issue of whether a company should recognize an expense when it grants an employee stock option for a fixed plan. Part of the disagreement may be the result of the definitions of assets, expenses, and equity as provided in Statement of Financial Accounting Concepts (SFAC) No. 6. Additionally, the profession may agree that both an asset is created and an equity instrument issued upon the granting of a stock option, but may disagree on how, or even if, its value can be measured. Comparability is compromised when transactions with similar economic consequences result in different accounting treatments. Essentially, the FASB has failed to deliver on its stated intention to provide neutral accounting information to assist 
users in assessing investment opportunities [Kirk, 1979].

The purpose of this paper is to explore alternative methods of accounting for stock options and to empirically evaluate the impact on financial statements of the alternatives discussed by the FASB. The remainder of this paper is organized as follows. First, we briefly discuss the current requirements for accounting for stock options. Next, we identify and test the models previously suggested by the FASB. Finally, we offer alternative approaches that we believe are superior for measuring compensation expense and are consistent with accounting for similar compensation packages.

\section{Background}

APB Opinion No. 25 requires that compensation expense for fixed stock option plans be measured as the difference between the market price and the exercise price on the measurement date. The measurement date is defined as the earliest date at which both the number of shares that an individual employee is entitled to receive and the exercise price are known. As a result of this treatment, no compensation expense is recorded for the issuance of fixed stock options for a majority of companies [Wallace, 1984]. Only if the market price exceeds the exercise price at the grant date will any compensation expense be recorded. If a compensation expense arises from the issuance of a stock option, then the employer must record the difference as a deferred compensation expense and allocate the compensation expense to the periods in which the services are performed.

In comparison, variable plans, such as stock appreciation rights (SARs), entitle an employee to receive cash, stock, or a combination based upon the appreciation of the market price above a selected, per share price over a specified period. The total compensation expense is determined at the measurement date, which for SARs is generally the exercise date. Between the grant date and the measurement date, the compensation expense must be estimated. The estimated compensation expense and associated liability are determined on a quarterly basis by multiplying the number of SARs by the difference between the market price of the stock and the SAR base price. Amortization is required over the lesser of the service or vesting period. However, after the service or vesting period ends, compensation expense continues to be adjusted with fluctuations in the market price until the SARs either expire or are exercised. Cumulative compensation expense, however, cannot be reduced below zero.

A comparison of these two employee compensation plans (fixed stock options and SARs) indicates that while the economic consequences appear to be identical, their accounting requirements and resultant income effects differ substantially. Under the current accounting treatment for fixed stock option plans, compensation expense is recorded only if the market price exceeds the exercise price at the grant date. Future fluctuations in market price do not affect compensation expense. By contrast, compensation expense for SARs varies on a quarterly basis with changes in the market price of the stock. Thus, the accounting treatment for SARs may result in wide fluctuations in net income depending on the volatility of the company's stock.

The first half of 1986 was a period of shifting attitudes at the FASB with regards to accounting for employee stock options and stock. awards. In January 1986, the FASB tentatively agreed that the compensation cost of stock options and stock award plans should be measured at the date of grant using a minimum value model [FASB, January 1986]. However, the $\overline{\text { FASB }}$ reversed its previous opinion in July 1986, tentatively agreeing that "compensation cost for stock option and stock award plans should be measured at the later of the vesting date (the first date at which an employee is entitled to receive and retain a stock award or has unconditional rights to a stock option) or the date 
at which certain measurement factors, including the number of shares and purchase price, are known. The Board also tentatively agreed that the measurement method is fair value with the rebuttable presumption that it is not less than the value determined by applying the minimum value model" [FASB, July 1986, p. 3].

The FASB initially embraced the minimum value method because it was believed to be conceptually sound, objectively determinable, and easily computed [Swieringa, 1987, p. 7]. The minimum value method suggested by the Board defines the minimum value of an option as the market price of the stock minus the present values of the exercise price and expected dividends, with a lower bound of zero. The minimum value of the option is a function of three variables (stock price, expected dividend rate, and time to expiration) and two parameters (exercise price and risk free rate of interest).

This method, while easy to use, contains several assumptions and limitations that restrict its applicability for valuing employee stock options. First, the model assumes that the risk free rate of interest is known, constant throughout the time period, and available to the borrower. Second, the model ignores taxes and transaction costs. Third, the model assumes that the stock option is held to maturity (i.e., European Option). However, employee stock options and awards differ from traded options in that they are not transferable and that they lapse upon termination of employment. Both of these restrictions undermine the assumption that the option will be held to maturity and thus, generally result in an overstatement of the option's value. More importantly, the minimum value model fails to incorporate the volatility of the underlying stock.

In the Discussion Memorandum, "Distinguishing Between Liability and Equity Instruments and Accounting for Instruments with Characteristics of Both" (FASB, 1990), the Board suggests that, in accounting for stock options, the distinction between whether an equity or liability results from issuing options is critical in determining the appropriate method of accounting for options (para. 69). It proposed that, if an option is considered an equity instrument, then the "...final measurement date for compensation expense will be the date at which the option is deemed to be issued" (para. 9). Thus, an option asset and equity are required to be recognized on the issue date and the corresponding expense related to the amortization of the asset to be recognized over the life of the option. This balance sheet approach results in asset and equity recognition at issue date.

On the other hand, if granting stock options is viewed as giving rise to a liability, the measurement date for the option would become the exercise date since "...changes in the amount or value of a liability after its incurrence do affect a debtor's net income" (para. 69). This income statement approach results in recognition of an option expense as the difference between the market price of the stock at exercise date and the exercise price of the stock. This expense would be periodically estimated and charged annually against income.

As a result of the limitations and criticism of the Minimum Value model, the FASB's 1993 Exposure Draft proposed that the fair value of a stock option could be estimated by using a pricing model such as the Black-Scholes model and that this fair value should be recorded as an asset and an equity on the balance sheet.

Fair value (exact) option pricing models, including the well known Black-Scholes model, incorporate the volatility of the underlying stock in the determination of the option's value in addition to the determinants already included in the minimum value model. However, fair value option pricing models suffer from many of the same limitations and deficiencies attributable to the minimum value model with one notable exception - fair value option pricing models include the underlying stock's volatility in the valuation of the option. Although the Black-Scholes model 
includes a volatility adjustment, it is still restricted to assuming a constant variance in the rate of return of the underlying stock [Black and Scholes, 1973].

As with the minimum value model, the Black-Scholes model assumes that the employee stock option is a European call option (i.e., one that can only be exercised at maturity). Employee stock options and awards, however, are different from traded options in that they are not transferable and that they lapse upon termination of employment. Both restrictions violate the assumption that the option will be held to maturity and thus can result in an overstatement of the option's reported value. In order to overcome this limitation the Board allows the option value to be determined by using its expected life.

Fair value option pricing models may provide the best possible estimation of an option's value given the inherent uncertainty involved. In the 1993 Exposure Draft, the FASB would "require recognition of compensation costs for the fair value of stock-based compensation paid to employees for their services" [FASB, 1993] rather than the minimum value of the option. Presumably, the Board believed the fair value model is relevant and reliable and will provide useful information to decision-makers.

In the 1993 Exposure Draft, the FASB proposed that an option asset and an equity be recognized in an amount equal to the Black-Scholes valuation of the option. The option asset would then be amortized over the life of the option. This "asset-equity" approach (a Balance Sheet approach) was proposed because amounts that are attributable to future service are viewed as representing a prepaid asset for compensation. Additionally, because the award for service is an equity instrument to employees, the fair value of the award is additional equity on the award date. According to the Exposure Draft, the issuance of options to acquire employee services represents an exchange of something of value (a stock option) for something of value (employee services).
Therefore, the FASB would have required recognition in the financial statements since nonrecognition "...produces financial statements that are neither credible or representationally faithful." (summary) In the Exposure Draft, the FASB asserted that option-pricing models produce estimates of the fair value of options which are reliable and relevant, thus justifying their recognition in financial statements.

SFAC No. 5 states that "disclosure is not a substitute for recognition in financial statements for items that meet recognition criteria" (para. 9). Thus, the Board in the Exposure Draft concluded that disclosure is not an acceptable method of presenting stock options.

As a result of the Exposure Draft, the FASB held six days of public hearings and received more than 1700 comment letters, the vast majority of which were opposed to including the amortization of the option asset as a yearly expense. In addition, the United States Senate adopted a non-binding sense of the Senate resolution expressing opposition to the Exposure Draft (May 3, 1994).

After a lengthy discussion of the alternatives for accounting for employee stock options, the FASB issued Statement of Financial Accounting Standards No. 123 that permits companies to continue to account for stock options and related arrangements under present rules which do not require recognition of an expense. This Standard requires improved disclosures of stock options in the notes to financial statements and encourages companies to adopt methods to account for stock compensation awards based on their fair value at grant date. However, in SFAS No. 123, the FASB reversed its previous position and called for disclosure of only the income effect of granting options. Neither the option asset nor the option equity is required to be disclosed. Thus, the Board abandoned its "balance sheet" approach and shifted to an "income approach" to accounting for options. Yet, it continued to require that the option expense be computed by de- 
termining the Black-Scholes option (asset) value and amortizing that (asset) value over the expected life of the option.

Since the option asset and resulting equity are not recorded, the income effect of the option expense could be measured by other methods that are more consistent with the "income approach." One such method, the exercise date model (Simple Model), measures the option expense for fixed plans in an analogous manner to that used in accounting for SARs. Under this approach, the total option expense is measured as the difference between the stock price at issue date and the stock price at exercise date. The periodic expense is then estimated between these dates by expensing the difference between the exercise price and the current market price. In subsequent years, the difference between the exercise price and the current market price is adjusted by the amounts previously expensed.

\section{Empirical Analysis}

The empirical analysis is designed to examine the sensitivity of reported compensation expense under the alternative methods proposed in the FASB's 1993 Exposure Draft. To do so, we select a sample of firms with outstanding stock options and compare the amount of annual compensation expense to be reported over a five-year period under each of these alternative methods. We also examine the impact on reported income of reporting compensation expense under each method.

Our analysis is conducted on a sample of 116 randomly selected calendar year-end firms with stock options outstanding on December 31, 1990. These firms were required to have information on the number of stock options outstanding in the stock options note to the 1990 financial statements which were obtained from the Compact Disclosure Database. Additionally, sample firms were required to have daily stock prices and returns from 1990-1995 available in CRSP. Those data are used for estimating price volatility, which is one of the variables in the Black-Scholes model. Finally, firms were required to have annual dividend information from 1990-1995 available in the Compustat PDE tape. There were 42 two-digit SIC industries represented in the sample. The maximum number of firms from any industry was 10 (General Industrial Machinery and Equipment).

The empirical analysis assumes that the options were granted on December 31, 1990 and are exercised five years later on December 31, $1995^{1}$. It also assumes that the exercise price is equal to the fiscal 1990 closing stock price. These assumptions allow determination of the number of options to be exercised and the market price of the stock at the exercise date. The "actual" compensation expense for options can be viewed as the difference between the market price of the stock on December 31, 1995 and the exercise price (which is the market price on December 31, 1990) times the number of outstanding options. This amount reflects the cash the firm has foregone by issuing stock options rather than by selling the shares in the market on the exercise date because it would then receive an amount equal to the market price on the exercise date instead of receiving an amount equal to the exercise price. It may be viewed as an expense since stock options are an integral part of employee compensation.

In addition to the above assumptions, the analysis also assumes annual dividends will equal 1990 dividends and that the five-year treasury note rate at December 31, 1990 is an appropriate measure of the risk-free interest rate. These variables are used as inputs to the Minimum Value and Black-Scholes models.

Since both the Minimum Value model and Black-Scholes model have been suggested at different times by the FASB as appropriate measures of the option value at the grant date, the empirical question is which model is the best predictor of the "actual" compensation for options. Using these models, we estimate the total 
compensation cost for the 1991-1995 period on December 31, 1990 and amortize that cost evenly over the five-year period. The annual compensation expense estimated using each of these models is then compared to the "actual" compensation expense. Thus, we compare ex ante estimated compensation expense using the Minimum Value and Black-Scholes models to ex post compensation expense which assumes knowledge of the December 31, 1995 market price.

Table I reports mean estimated annual compensation expense for the sample based upon the Black-Scholes model including dividends and the Minimum Value model ${ }^{2}$. It also reports ex post annual compensation expense. The results reported in Table I show that compensation expense based on the Black-Scholes model with or without dividends is considerably greater than the ex post actual compensation expense. The mean expense for the Black-Scholes model with dividends of $\$ 34.07$ million exceeds the ex post value of $\$ 24.49$ million by 39.1 percent. The mean expense for the Black-Scholes model without dividends is even greater. It exceeds the ex post expense by 49.2 percent. Unlike the BlackScholes models, compensation expense based on the Minimum Value model is considerably lower. The sample mean of $\$ 3.95$ million is 83.9 percent lower than its ex post value.
These results suggest that there is a wice variation in the compensation expense that will be recorded under the Black-Scholes and the Minimum Value models. While the BlackScholes model significantly overestimates the actual compensation expense, the Minimum Value model significantly underestimates it. It should be noted that the magnitude and direction of the misestimation are dependent on the behavior of stock prices from the grant date until the exercise date. Perhaps an even more important result of this analysis is that neither model accurately estimates the actual compensation expense.

To provide some indication of the significance of the estimated compensation expense using these models, we examine the percentage change in annual earnings before taxes that would result from subtracting the alternative measures of compensation expense. The mean percentage decrease is 12.5 percent for the Black-Scholes model with dividends, and 1.4 percent for the Minimum Value model ${ }^{3}$. If the ex post annual compensation expense is subtracted, the mean percentage decrease is 8.5 percent. These values indicate that there is a sizable decrease in income that would result from recognizing compensation expense, especially if the Black-Scholes model is used for measuring it. The results also suggest that the current accounting method of not recognizing compensation ex-

\begin{tabular}{||l|l|l|l||}
\hline \multicolumn{4}{|c|}{ Table I } \\
\hline \hline \multicolumn{4}{|c|}{ Estimated Annual Compensation Expense Using Alternative Models Period: 1991-1995 } \\
Models estimated on December 31, 1990
\end{tabular}

a. Mean annual compensation expense is the sample average compensation expense estimated using each model.

b. Actual represents the ex post option value allocated evenly over the 1991-1995 period. Ex post option value is determined as the market price on December 31, 1995 (the assumed exercise date) minus the market price on December 31, 1990 (the assumed grant date).

c. The Black-Scholes and Minimum Value models are used to estimate the option value on December 31, 1990. The estimated option value is then allocated evenly over the 1991-1995 period. 
pense when the exercise price is greater than or equal to the market price on the grant date has the potential for significantly overstating reported earnings. Based on these results, there is considerable merit in the FASB proposal to recognize compensation expense related to the granting of employee stock options; however, the appropriate method of measuring the expense is not clear.

\section{Sensitivity of Black-Scholes Estimates}

A major criticism of the Black-Scholes method of valuing stock options is the sensitivity of the estimates to the model's inputs. The most critical of these inputs is the instantaneous stock price variance which is often measured as the stock price volatility estimated from daily stock. price data. The number of days used to measure daily price volatility can cause it to vary widely and, therefore, significantly alter the estimate of compensation expense. Consequently, we exam. ine the sensitivity of the Black-Scholes model's estimates of compensation expense to alternative measurement periods for price volatility.

We estimate annual compensation expense using the Black-Scholes with dividends model with price volatility measures estimated using $30,60,90,120$ and 240 trading day periods. The results indicate a very low sensitivity to these alternative price volatility estimates with mean annual compensation expense varying from $\$ 33.87$ million for the 30-day estimation period to $\$ 34.21$ million for the 90 -day estimation period. Much of the criticism of the FASB's 1993 proposal focused on the sensitivity of the BlackScholes model's estimates to alternative measurement periods for price volatility. The results of our empirical analysis indicate that such criticism may be unwarranted.

\section{Alternative Approaches}

The results reported in Table I indicate that - neither the Black-Scholes nor the Minimum Value model is a good predictor of actual com- pensation expense. While the Black-Scholes model significantly overestimates compensation expense, the Minimum Value model significantly underestimates it. One alternative approach is to estimate total compensation cost at the end of each year (i.e., December 31, 1991, December 31, 1992, December 31, 1993, December 31, 1994 and December 31, 1995) and use the most recent estimate to revise the amount of compensation expense to be recognized in each year of the service period (which is five years in our study). This approach, which is similar to that currently employed for SARs, treats the reestimated compensation cost as a change in accounting estimate. Under this approach the Black-Scholes and Minimum Value models are used each year to re-determine the option value. The expense schedule is then adjusted based on this updated valuation. In addition to reestimating compensation expense each year under the Black-Scholes and Minimum Value models, we also employ an alternative "Simple" model approach which estimates total compensation cost as the year-end stock price less the exercise price times the number of options. This compensation cost is then divided by the remaining life of the option to determine the annual expense. In subsequent years, this value is recomputed based on current closing price. Any changes in value are treated as a change in accounting estimate. This "Simple" approach is basically the same method currently used in accounting for stock appreciation rights. The same total amount of compensation expense is recognized over the five-year period for each model. It equals the difference in market price on December 31,1995 and the exercise price (which is the market price on December 31, 1990) times the number of outstanding options on December 31,1990 . But while the total compensation expense over the five-year period is the same for all models, the expense recognized in any given year may differ across models.

Mean annual compensation expense for 1991-1995 under the Black-Scholes model with dividends, the Minimum Value model and the 
Simple model are reported in Table II. Perhaps the most striking feature of these results is the pattern of recognition of compensation expense over the five-year period across the different models ${ }^{1}$. For the Black-Scholes model, compensation expense recognized declines dramatically over the five-year period. Contrary to the Black-Scholes model, 95 percent of the total compensation cost is recognized in 1995 under the Minimum Value model. The Simple model also generally demonstrates an increasing pattern of compensation expense from 1991 to 1995. However, the amount recognized in 1995 is considerably less than that recognized under the Minimum Value model. Compensation expense recognized under the Simple model is primarily dependent on the direction of stock price changes from one year to the next. In a period of declining prices, the amount of compensation expense recognized will be less than in the previous period. This is illustrated in the results reported in Table II. Compensation expense increased in 1991, 1992, 1993 and 1995, when stock prices increased, whereas it decreased in 1994 when stock prices decreased. ${ }^{2}$

\section{Additional Sensitivity Analysis}

The evaluation of alternative models' per- formance reported in the preceding sections is based on conditions prevailing during the period, 1991-1995. To the extent that economic conditions during this period are not representative, the results of our analysis may be periodspecific. Consequently, they may not be generalizable to other periods. To examine the sensitivity of our results to alternative economic conditions, we repeated the analysis over the 19861990 period for the same 116 firms used in the primary analysis. This analysis assumes that the options were granted on December 31, 1985 and are exercised five years later on December 31 , 1990. Using the Minimum Value model and the Black-Scholes model, we estimate the total compensation cost for the 1986-1990 period on December 31, 1985 and amortize that cost evenly over the five year period.

Table III reports mean estimated anmual compensation expense for the sample based upon the Black-Scholes model with dividends and the Minimum Value model. It also reports ex post annual compensation expense. The results are similar to those reported in Table I and show that compensation expense based on the BlackScholes model with dividends is considerably greater than the ex post actual compensation expense. The mean expense for the Black-Scholes

\begin{tabular}{|c|c|c|c|c|c|}
\hline \multicolumn{6}{|c|}{ Table II } \\
\hline \multicolumn{6}{|c|}{$\begin{array}{c}\text { Estimated Annual Compensation Expense Using Alternative Models Period: 1991-1995 } \\
\text { Models re-estimated annually on December } 31 \text { (1990-1994) }\end{array}$} \\
\hline Model & 1991 & 1992 & 1993 & 1994 & 1995 \\
\hline Black-Scholes & $\$ 42.23$ & $\$ 32.65$ & $\$ 23.07$ & $\$ 13.49$ & $\$ 11.01$ \\
\hline Minimum Value & $\$ 2.58$ & $\$ 1.96$ & $\$ 1.32$ & $\$ \quad .68$ & $\$ 115.91$ \\
\hline Simple & $\$ 11.16$ & $\$ 16.74$ & $\$ 28.76$ & $\$ 25.72$ & $\$ 40.07$ \\
\hline $\begin{array}{l}\text { Percentage change in NYSE Composite } \\
\text { Index from beginning of year-to-end-of-year }\end{array}$ & 26.9 & 4.8 & 7.9 & -3.1 & 33.3 \\
\hline
\end{tabular}

a Dollar amounts represent sample average compensation expense using each model.

b The Black-Scholes and Minimum Value models are re-estimated each December 31, 1990-1994. Reestimated option values are then used to compute compensation expense by allocating the estimated option value not recognized as yet to the remaining periods in the life of the option.

c The Simple model estimates the option value as the difference in year-end market price and market price on December 31, 1990 (the assumed exercise date). It then allocates the estimated option value not recognized as yet to the remaining periods in the life of the option. 
model with dividends of $\$ 16.76$ million exceeds the ex post value of $\$ 11.12$ million by 33.7 percent.

Unlike the Black-Scholes model, compensation expense based on the Minimum Value model is considerably lower. The sample mean of $\$ 6.84$ million is 38.5 percent lower than its ex post value. Again, the results suggest that there is a wide variation in the compensation expense that will be recorded under the Black-Scholes and the Minimum Value models.

Mean annual compensation expense for 1986-1990 under the Black-Scholes model, the
Minimum Value model and the Simple model are reported in Table IV. The pattern of recognition of compensation expense over the five-year period across the different models is similar to that seen in Table II. For the Black-Scholes model, compensation expense recognized declines over the five-year period. Contrary to the BlackScholes model, 72 percent of the total compensation cost is recognized in 1990 under the Minimum Value model. The Simple model demonstrates an increase in compensation expense from 1986 to 1989 when stock prices increased, and a decrease from 1989 to 1990 , reflecting the decline in stock market price movement.

\begin{tabular}{||c|l|l|l||}
\hline \multicolumn{5}{|c|}{ TabIe III } \\
\hline \hline \multicolumn{4}{|c|}{ Estimated Annual Compensation Expense Using Alternative Models Period: 1986-1990 } \\
Models estimated on December 31, 1985 & Minimum Value \\
\hline & Actual & Black-Scholes & $\$ 6.84$ \\
\hline Mean Annual Compensation Expense & $\$ 11.12$ & $\$ 16.76$ & \\
\hline
\end{tabular}

a. Mean annual compensation expense is the sample average compensation expense estimated using each model.

b. Actual represents the ex post option value allocated evenly over the 1986-1990 period. Ex post option value is determined as the market price on December 31, 1990 (the assumed exercise date) minus the market price on December 31, 1985 (the assumed grant date).

c. The Black-Scholes and Minimum Value models are used to estimate the option value on December $31,1985$. The estimated option value is then allocated evenly over the 1986-1990 period.

\begin{tabular}{|c|c|c|c|c|c|}
\hline \multicolumn{6}{|c|}{ Table IV } \\
\hline \multicolumn{6}{|c|}{$\begin{array}{l}\text { Estimated Annual Compensation Expense Using Alternative Models Period: 1986-1990 } \\
\text { Models re-estimated annually on December } 31 \text { (1985-1989) }\end{array}$} \\
\hline Model & 1986 & 1987 & 1988 & 1989 & 1990 \\
\hline Black-Scholes with dividends & $\$ 17.89$ & $\$ 12.25$ & $\$ 10.89$ & $\$ 8.92$ & $\$ 5.65$ \\
\hline Minimum Value & $\$ 5.98$ & $\$ 4.78$ & $\$ 3.21$ & $\$ 1.61$ & $\$ 40.02$ \\
\hline Simple & $\$ 5.54$ & $\$ 7.92$ & $\$ 10.11$ & $\$ 19.08$ & $\$ 12.95$ \\
\hline $\begin{array}{l}\text { Percentage change in NYSE } \\
\text { Composite Index. }\end{array}$ & 14.0 & 0.3 & 12.4 & 27.3 & -6.6 \\
\hline
\end{tabular}

a. Dollar amounts represent sample average compensation expense using each model.

b. The Black-Scholes and Minimum Value models are re-estimated each December 31, 1985-1989. Reestimated option values are then used to compute compensation expense by allocating the estimated option value not recognized as yet to the remaining periods in the life of the option.

c. The Simple model estimates the option value as the difference in year-end market price and market price on December 31, 1985 (the assumed exercise date). It then allocates the estimated option value not recognized as yet to the remaining periods in the life of the option. 


\section{Summary and Conclusions}

The purpose of this paper is to review and empirically test alternative measures of accounting for stock options under various proposals made by the Financial Accounting Standards Board. In order to reach a palatable compromise, forced upon the Board by strong opposition from Congress and the Corporate lobby, the FASB, in Statement of Financial Accounting Standards No. 123, shifted from its previously reasoned Balance Sheet approach of reporting the option asset, equity and expense to an Income Statement focus which only requires disclosure of the expense in the footnotes to the financial statements. However, the FASB required that the measurement of the expense be based upon amortization of the option asset. In so doing, it failed to make the required measurement of the expense consistent with the required approach to its disclosure.

The FASB's 1993 Exposure Draft would have required that the fair value of employee options be recorded as an asset and a corresponding equity as of the grant date (balance sheet approach). The asset would then be amortized over the time period the option is outstanding. Employee options represent "...probable future benefits because employees have agreed to render future services to earn their options. Stock options also reduce future cash outflows otherwise necessary to compensate employees." (Exposure Draft Summary, p. 1) Thus, the Exposure Draft viewed stock options as an executory contract in which the firm offered options to employees for their continuing service. Options may also reduce future cash outflows since they can be used to reduce the need for future wage increases.

SFAS No. 123 encourages, but does not require companies to record the compensation expense. Companies that choose not to adopt the new rules will continue to apply the existing accounting rules contained in APB Opinion No. 25 , and will disclose the impact on net income and earnings per share. Thus, for most companies, the current standard modifies the assetequity approach of the exposure draft to an income approach, yet it continues to require that the option expense be computed by apportioning the cost of the option asset over the expected life of the option. Only the income effect need be disclosed in the financial statements.

Since the pronouncement does not require the option asset and equity values to be disclosed, the approach suggested by the FASB appears inconsistent with the expense measurement. If there is no option asset and corresponding equity at issue date then the measurement of the expense should be based upon the periodic measure of what is being given up by granting employee options (i.e., the effect on future cash flows).

The FASB suggests use of a static measure of the future expense of options. Dynamic measures, which incorporate information about future stock movements, would provide expense estimates that convey more meaningful information.

Our results suggest that an exercise date model (Simple Model) approach provides such a measure of option expense in addition to being consistent with the current method of accounting for SARs. If option expense is viewed as the difference in cash flows from granting options, the total expense will be equal to the difference between the market price of the stock at the exercise date and the option price. Unlike the exercise date model, our results indicate that the Black-Scholes model tends to front-end the reporting of this "cash flow" expense whereas the Minimum-Value model tends to back-end this expense.

An alternative dynamic approach would be to re-estimate the value of the option asset at the end of each year using the Black-Scholes model and to use the updated estimate to revise the amount of compensation expense to be recog- 
nized in each subsequent year. This approach treats the re-estimate as a change in accounting estimate.

Stock options are granted for several reasons. They represent deferred employee compensation which can have favorable tax treatment to the individual. Options allow employees to become owners of the business at a favorable price. They offer incentives to employees to improve firm performance, thereby benefiting the owners of the firm.

From the employees' perspective, the option takes on value when the market price of the stock exceeds the exercise price. From the firms' perspective, "costs" are incurred when stock is sold to the employees at the reduced price since the firm gives up cash it could have received by selling shares in the market instead of to employees. Thus, future market conditions are relevant to both the employee and the employer. Attempts to measure future costs without incorporating the most current market conditions can result in less reliable estimates. While the Board asserts that option-pricing models provide reliable and relevant information, failure to update and revise estimates ignores current information that may be relevant to those estimates. Furthermore, their recommended approach is not consistent with accounting for other estimated expenses.

Fair Market value option models like the Black-Scholes model were developed to value options for the short-term, generally 30-90 days. Employee stock options are usually issued for 310 year time periods. Consequently, BlackScholes and similar models may be poor predictors of long-range option values. The results of our empirical analysis indicate that neither the Black-Scholes model nor the Minimum Value model provides accurate estimates of compensation expense. Whereas the Black-Scholes model recognizes a majority of the expense early in the option's life, the Minimum Value model recognizes most of the expense late in the life of the option. Even after updating the Black-Scholes estimates to reflect current market conditions, the model still front-ends the compensation expense. In contrast, estimates of compensation expense using the Simple model proposed in this study are considerably more accurate that those obtained with either the Black-Scholes model or the Minimum Value model.

Based upon the results of our study, we conclude that the Simple model is more appropriate for measuring compensation expense. It is easy to use and to understand. It can be adjusted to reflect current information and market conditions. It is consistent with the method currently used to account for stock appreciation rights. Finally, it provides financial statement users with a reliable measure of the cash given up by issuing stock options rather than selling the stock in the market.

\section{Suggestions for Future Research}

In this study we focused on the effect of alternative methods of computing the option expense in annual reports. Two time periods were used, 1991-1995 and 1986-1990. Given the explosion of stock prices in recent years, it would be interesting to re-run the study for the period 1996-2000. Our paper only attempted to measure the annual effect of the option expense. Since financial information on earnings is reported quarterly, one possible extension would be to study the effect on quarterly earnings. Another extension would be to look at other market models other than Black-Scholes in measuring option expense.

\section{Endnotes}

1. While employee stock options are generally issued for periods from three to ten years, most are exercised early. Five years would appear to be a reasonable estimate of the average time an option is outstanding. We also conducted the analysis assuming that options would be outstanding for three years. Al- 
though the numerical estimates differ, the results are qualitatively similar to those reported for the five-year assumption.

2. We also estimated the amount of compensation expense using the Black-Scholes model excluding dividends. All of the results for the Black-Scholes model without dividends are similar to those for the Black-Scholes model with dividends. To avoid redundancy, we only report results for the Black-Scholes model with dividends.

3. We excluded one observation which reflected a 418 percent decrease in earnings from the computation of these mean estimates.

4. This is not unexpected as the time to expiration of the option is positively related to its value under the Black-Scholes model. This is so because the probability of the stock price exceeding the exercise price decreases as the option nears expiration.

5. The annual percentage changes in average stock price for our sample corresponded closely with the percentage changes in the NYSE Stock Price Index over this period, indicating that price movement for our sample is representative of general price movement in the larger market.

\section{References}

1. American Institute of Certified Public Accountants, "Accounting for Stock Issued to Employees," Accounting Principles Board No. 25 (October 1972).

2. Accounting Principles Board, "Accounting for Compensation in the Form of Stock Options," Accounting Research Bulletin No.
37, (New York: American Institute of Certified Public Accountants, November 1948).

3. Black, F., and M. Scholes, "The Valuation of Option Contracts and a Test of Market Efficiency," The Journal of Finance 27 (May 1973, 399-417).

4. Financial Accounting Standards Board, "Accounting for Stock Appreciation Rights and Other Variable Stock Option or Award Plans," FASB Interpretation No. 28 (December 1978).

5. Financial Accounting Standards Board "Accounting for Stock Options," FASB (1986).

6. Financial Accounting Standards Board "Exposure Draft Accounting for Stock-based Compensation," FASB (1993).

7. Financial Accounting Standards Board, "Statement of Financial Accounting Standards No. 123, Accounting for Stock-Based Compensation," FASB (1995).

8. Hemmer, T., S. Matsunaga, and T. Shevlin, "Estimating the "Fair Value" of Employee Stock Options with Expected Early Exercise," American Accounting Association, Accounting Horizons Vol. 8, No. 4, (December 1994), pp. 23-42.

9. Kirk. D. J., "Private Standard Setting and Public Accountability," FASB Viewpoints (October 1979).

10. Swieringa, R. J., "Accounting for Stock Options," FASB Status Report No. 183 (January 20, 1987), pp. 6-10.

11. Wallace, Wanda A., "The Effects of Delays by Accounting Policy-Setters in Reconciling the Accounting Treatment of Stock Options and Stock Appreciation Rights," The Accounting Review (April 1984), pp. 325-341. 